\title{
Garantías en el ejercicio de un derecho social en el marco de una difuminada relación entre público y privado: no da lo mismo
}

\author{
Guarantees according to a social right in the framework of a blurred \\ public-private relationship: it makes difference \\ Carmen MonTAlBÁ OCAÑA \\ Universitat de València \\ carmen.montalba@uv.es
}

Recibido: 09/02/2013

Revisado: 19/03/2013

Aceptado: 16/05/14

Disponible on line: $27 / 06 / 2014$

\begin{abstract}
Resumen
La implementación de la Ley de Promoción de la Autonomía personal y Atención a las personas en situación de Dependencia (LAPAD), en la Comunidad Valenciana ha sido un escenario privilegiado para la observación y el análisis del impacto de la relación entre público y privado en un derecho social reconocido.

Este artículo condensa algunas de las conclusiones que derivan del estudio de caso sobre el ciclo de vida de esta Ley en la Comunidad Valenciana durante el periodo 2006-2012. El objetivo de esta investigación es identificar las razones que contribuyen a incrementar la brecha entre la formulación legal y su efectiva implementación.

Los resultados obtenidos fijan la atención en aquellas dimensiones que remiten al modelo institucional que acoge el derecho social y aquellas condiciones que posibilitan o dificultan su pleno ejercicio, siendo uno de los obstáculos identificados en el reconocimiento y ejercicio del derecho la relación público-privada en la política social valenciana.

Palabras clave: servicio público, privatización, derechos sociales, situación de dependencia, cultura de la legalidad.
\end{abstract}

\begin{abstract}
The implementation of the Law on Promotion of personal autonomy and care for dependent persons (LAPAD) in Valencia has been a privileged stage for the observation and analysis of the impact of the relationship between public and private in a social right recognized. This article condenses some of the conclusions derived from the case study about the LAPAD life cycle in Valencia during the period 2006-2012. The objective of this research is to identify the reasons that contribute to increase the gap between the legal formulation and effective implementation. The results have focused on those dimensions that refer to the institutional model of the social law and the conditions that enable or impede the full exercise of the law. The public-private relationship in the Valencia social policy context has been identified as one of the obstacles in the recognition and accomplishment of the law.
\end{abstract}

Keywords: public service, privatization, social laws, dependency, culture of legality.

Referencia normalizada: Montalbá Ocaña, C. (2014): «Garantías en el ejercicio de un derecho social en el marco de una difuminada relación entre público y privado: no es lo mismo». Cuadernos de Trabajo Social, 27(1): 165-174.

Sumario: 1. Definición de «lo público». 2. Debilitamiento de las fronteras entre «lo público» y «lo privado». 3. No da lo mismo. 4. Referencias bibliográficas.

\section{Definición de «lo público»}

En un escenario tan complejo como ha sido la puesta en marcha de la Ley de Promoción de la autonomía personal y atención a las personas en situación de dependencia, tanto en su proce- so de gestación como en su aplicación, se admitió de forma natural la cuestión de la incorporación de agentes privados como «operadores» del sistema, tal y como expresan los artículos 6.2 y 15 de la Ley ${ }^{1}$.

1 «El sistema se configura como una red pública que integra, de forma coordinada, centros y servicios públicos y privados» (art.6.2). «Los servicios del catálogo se prestarán a través de la oferta pública del sistema, mediante centros y servicios públicos o privados concertados» (art. 15). 
Pese a no ser un fenómeno nuevo, la ley ha permitido en la Comunitat Valenciana una mayor presencia en el escenario de nuevas fórmulas de relación público-privadas que han afectado al reconocimiento y ejercicio del derecho social y, sobre todo, a las propias posibilidades que la ciudadanía ha tenido para defenderlo y reivindicar que se garantice.

Para valorar este impacto, en primer lugar cabría interrogarse sobre aquello que denominamos servicio público. Una definición bastante completa la ofrece Bautista (2007), refiriéndose a: «aquella actividad ofrecida por el conjunto de instituciones que conforman la administración pública cuyo objeto consiste en facilitar de modo regular, continuo y sin propósito de lucro, la satisfacción de una necesidad colectiva o de interés general» (p. 42).

Esta acepción limita el carácter del servicio público a aquel que es provisto por la administración y se orienta al interés general. Sin embargo, en párrafos posteriores, el mismo autor la amplía, asumiendo que el servicio se puede proporcionar de manera directa, por medio de los órganos administrativos, o de forma indirecta, cuando el Estado cede a terceros la facultad de prestar determinados servicios públicos sobre las bases establecidas por él.

El concepto que se mantiene, por tanto, es el de «interés general», definido por Álvarez (2010) como «aquellos objetivos materiales o espirituales cuya consecución o preservación se estima conveniente o necesaria para la comunidad, entendida ésta como un conjunto representativo de individuos integrado en la sociedad» (p. 39).

En la lectura de aquello que se entiende por «lo público» persisten una serie de rasgos que remiten a la intervención gubernamental, sometida a derecho administrativo y orientada por un interés general. Algunos autores incluirán, además, a este listado el término "solidario» aunque, de nuevo, cabe subrayarse que dichos conceptos son asumidos con diferentes matices en los diferentes modelos de Estado (Estado liberal, socialdemócrata o relacional).

El último componente enunciado, relativo a la «solidaridad», se relaciona con la consideración que Álvarez-Uría (2002) realiza de la «propiedad social», entendida como «la propiedad de todos avalada por el Estado de Derecho y, por tanto, es la única propiedad de la que efectivamente gozan los no propietarios, la gente sin condición» (p. 16). Así, el Estado Social no abolió la propiedad privada, pero creó la propiedad social.

Respecto a los primeros componentes de la definición (intervención gubernamental y sometida al derecho administrativo), la historia ha dado cuentas de una tendencia hacia una acepción más laxa, abandonando la idea de que gravite bajo la persona jurídica de la administración.

De esta forma, se llega incluso a admitir en la propia definición de servicio público al sector privado, tal como expresan Tornos y Galán (2007):

La actividad prestacional podrá ser llevada a cabo en concurrencia con el sector privado, y este sector podrá integrarse en el sistema público para prestar la actividad que se califica de servicio público a través de alguna de las formas de gestión indirecta del servicio.

La privatización consiste, según Etxezarreta (2009), en convertir en un bien privado, individualizable, el uso de un bien «público».

Otra evidencia de esta mayor laxitud en la interpretación de aquello que es un «servicio público» es la amalgama de privatizaciones a las que puede verse sometido. Así, la Organización Internacional de Sindicatos que representan los Servicios Públicos (ISP, 1999) propone una clasificación de diferentes modalidades de privatización, acogiendo una multiplicidad de supuestos: privatización de la propiedad, de la responsabilidad, de una prestación, de la financiación, a través de los mercados (licitación competitiva entre subcontratistas públicos y privados, la libertad de elección para los/as pacientes y la separación entre personas adquiridoras y proveedoras) .

En España el ámbito de los servicios sociales se ha constituido como un buen laboratorio para experimentar fórmulas de privatización propias de otros sectores económicos desde la década de 1990, llegando incluso a resultar difícil saber dónde empieza lo público y acaba lo privado, tal y como se describe a continuación.

\section{Debilitamiento de las fronteras entre «lo público» $\mathbf{y}$ «lo privado»}

Como ya se ha señalado, las fórmulas de privatización han ido cambiando y haciéndose más complejas, no remitiendo sólo al traspaso de la 
gestión. En este sentido, Moreno (2002, p. 96) plantea que la evolución progresiva de los Estados de bienestar socialdemócratas hacia la aparición de servicios públicos de gestión privada acabaría por desvincular los aspectos orgánicos y funcionales del servicio público, posibilitando que organismos no administrativos pudieran gestionar un servicio público y delimitando el concepto de empresa privada de interés público y la gestión privada de servicios públicos de régimen mixto.

Por lo tanto y como el mismo autor apunta, el concepto de servicio público entra en crisis puesto que los tres elementos que dotan de contenido a su definición y emergen unidos de manera indisociables (organismo administrativo responsable, orientado al interés general y sometido al régimen jurídico) se disocian a gusto de quién los interpreta, apareciendo tres posibles definiciones diferenciadas según Moreno (2002, p. 97): la cuestión orgánica, que lo identifica con el conjunto de medios personales y materiales que la Administración orienta al logro de un determinado objeto; la cuestión funcional, actividad de interés general asumida por la administración; y la jurídica, cierto régimen jurídico propio de los servicios públicos.

La investigación llevada a cabo da muestras de esta fragmentación en la definición del servicio público, y de las diferentes fórmulas de privatización a través de mecanismos como: los instrumentos de financiación indirecta (prestación vinculada al servicio); las contrataciones y subcontrataciones en la prestación de servicios bajo diferentes modalidades; la inversión y gestión privada de centros (Plan de Accesibilidad Social); o la gestión externalizada de la Agencia Valenciana de Prestaciones Sociales S.A. (AVAPSA), entre otros. Más allá de representar fórmulas de privatización, también constituyen buenos ejemplos de lo que está siendo en nuestros días la difícil diferenciación «público-privado», tal y como paso a detallar.

\subsection{Fórmulas híbridas}

Como ya se ha citado, una de las fórmulas que dificultan la diferenciación público-privada se refiere a los denominados «instrumentos de financiación indirecta», como son los bonos, cheques o su equivalente en la Ley de Dependencia: la prestación vinculada al servicio ${ }^{2}$. Esta modalidad representa la prestación económica directa al ciudadano para que acceda al mercado.

Según Sajardo (1996), los principios básicos de este instrumento son: la libre elección de la persona usuaria, el reparto extensivo de los recursos intentando que éstos lleguen al máximo de individuos posible, además de traslado de la función de control y evaluación del servicio al/la ciudadano/a. Sin embargo, estos principios no son reales en la práctica, tanto por la imperfección de la información como por la propia escasez de la oferta que, en muchos servicios, obliga a la permanencia en una lista de espera, estando sujeta la elección de la persona meramente al primer recurso que muestre disponibilidad. Así, en la mayor parte de las ocasiones, aquello que se denomina «libertad de elección» se concreta en mera disponibilidad de recursos.

Vemos que, pese a que la fórmula administrativa supone la relación entre la persona y la empresa, en la práctica implica la relación entre la Administración y la empresa, siendo un mecanismo que opera de forma similar a cualquier contrato mientras que, por su parte, deja a la ciudadanía en una situación de inferioridad frente al mercado, puesto que debe cubrir una necesidad perentoria con una prestación que, en la mayor parte de los casos, sólo soporta un tanto por ciento del valor real del servicio, sintiéndose la persona beneficiaria obligada a someterse a las condiciones que le impone la empresa (autorizada a tal efecto por la administración) sin ningún poder real de negociación.

Otra de estas modalidades «híbridas» que ha desatado mucha polémica es la empresa pública, Agencia Valenciana de Prestaciones Sociales S.A. Esta empresa asumió una gran parte de funciones en el procedimiento de reconocimiento del derecho, motivando denuncias de los sindicatos, al considerar que una sociedad mercantil no podía asumir funciones de potestad administrativa.

${ }^{2}$ Definida en el artículo 16.2 de la Ley 39/2006 como prestación económica vinculada a la adquisición de un servicio, que tendrá carácter periódico, se reconocerá únicamente cuando no sea posible el acceso a un servicio público o concertado de atención y cuidado, en función del grado y nivel de dependencia y de la capacidad económica del beneficiario. 
En definitiva, la Agencia Valenciana de Prestaciones Sociales S.A. se encuadraría en este tipo de organizaciones que no puedan definirse en puridad ni como públicas ni como privadas, puesto que consisten en una combinación de elementos privado-públicos, para lo cual no hay que perder de vista los diferentes niveles de subcontratación a los que se ha acogido su actividad.

Al respecto, la Ley 62/2003 de 30 de diciembre, de medidas fiscales, administrativas y del orden social, en materia de contratos de la Administración Pública plantea, en el apartado uno del artículo 2 y en la disposición adicional sexta, la necesaria sujeción a la normativa de contratos públicos de todas las entidades de capital público o controladas por una Administración, aún cuando posean forma privada. En el caso de la Agencia valenciana ya se ha demostrado que tampoco ha existido una sujeción a la misma, sin la publicación de algunos de los contratos realizados, desarrollándose bajo la fórmula de encomienda de gestión.

Hay que destacar que las valoraciones de las situaciones de dependencia fueron externalizadas a esta empresa pública, incumpliendo el art. 28.6 de la Ley $39 / 2006^{3}$ donde se hacía explicito que son las administraciones públicas las directamente responsables de realizar esta labor. Los/as profesionales encargados/as de la valoración han sido personal no funcionario que en gran medida desconocía el procedimiento administrativo.

La Ley 10/2006 de 26 de diciembre ${ }^{4}$, representa el marco legal que faculta a la Generalitat para constituir tales organismos, y en su artículo 59 establece que esta sociedad mercantil presta servicios esenciales en materia de servicios sociales y de carácter sociosanitario. Y expresamente, en el apartado 3 de este artículo, se explica que la «actuación de AVAPSA no podrá suponer el ejercicio de potestades administrativas».

La diferencia fundamental que aporta esta entidad al marco normativo citado es que no implica la externalización en la prestación de servicios sino la asunción de funciones que son interpretadas por algunos/as versados/as en Derecho como funciones de responsabilidad pública y potestad administrativa, como es el caso de la valoración de las situaciones de dependencia, incumpliéndose de esta manera el régimen jurídico de la propia Agencia regulado en la Ley 10/2006 anteriormente citada.

$\mathrm{Si}$ ya es dudoso que una mercantil asuma funciones de responsabilidad pública, lo es más que las subcontrate y que lo haga bajo las fórmulas de encomienda de gestión sin publicitación de los contratos. Éstas han sido algunas de las cuestiones que, además de alimentar la polémica, han resultado ser valiosos indicadores de la falta de transparencia con las que operan estas fórmulas híbridas, convirtiéndose en cajas negras inexpugnables para la ciudadanía.

Otro ejemplo que evidencia la hibridación entre lo público y lo privado en el caso valenciano ha sido el modelo que se ha ido imponiendo en las residencias con nuevas fórmulas como el partenariado público y privado (PPP), con contratos de externalización a largo plazo, conocido como el denominado «Plan de Accesibilidad Social» o «Plan 9000» porque suponía la salida a concurso de la creación de 9.000 plazas residenciales para personas mayores, a través de la fórmula del contrato administrativo especial (DOGV de 8 de febrero de 2001). Desde este Plan se estimuló la creación de uniones temporales de empresas e incluso la creación de empresas ex profeso orientadas a la construcción de residencias y después a la gestión privada de las mismas.

El plazo que se contemplaba para alcanzar estas 9.000 plazas era de 15 años (del año 2001 al 2016) pudiéndose prorrogar por periodos de 5 años, sin exceder la duración total del contrato, incluidas la prórrogas, los 25 años (hasta el 2030). Lo máximo que permitía construir el contrato por cada centro eran 140 plazas, un tercio de las cuales debía estar a disposición de la Conselleria de Bienestar Social para ocupa-

3 Art. 28.6 de la Ley 39/2006: «Los servicios de valoración de la situación de dependencia, la prescripción de servicios y prestaciones y la gestión de las prestaciones económicas previstas en la presente Ley, se efectuarán directamente por las Administraciones Públicas no pudiendo ser objeto de delegación, contratación o concierto con entidades privadas»».

4 Ley 10/2006, de 26 de diciembre, de Medidas Fiscales, de Gestión Administrativa y Financiera, y de Organización de la Generalitat. Publicada en el DOGV n 5.416 de 28 de diciembre de 2006. 
ción y gestión pública. El resto podían adjudicarse libremente al precio que el adjudicatario considerara oportuno (son enteramente privadas). Así, este programa preveía que de las 9.000 plazas que se crearan, 3.000 serían directamente «de accesibilidad pública».

Entre las obligaciones que se fijaba la Administración en el contrato se establecía que

Se proporciona a los adjudicatarios de las respectivas zonas, exclusividad en la gestión de nuevas plazas residenciales para personas mayores dependientes en la correspondiente demarcación, absteniéndose de subvencionar la atención residencial de nuevas personas mayores en centros ajenos a los adjudicatarios, mientras éstos tengan plazas disponibles.

Esta «garantía de exclusividad» supuso, en un principio, cierto recelo de la patronal que tenía plazas a disposición pública, por ejemplo, por la vía del bono-residencia.

Un aspecto a destacar es el salto cualitativo que representa esta modalidad en la medida que no se refiere sólo a una privatización en la gestión, sino también del estímulo (reducción de impuestos, cesión de suelo público munici- pal y los beneficios en su imagen) a la inversión privada en infraestructuras que van a ser cedidas para su uso público, tal y como retrata la prensa del momento (Levante, 20/12/2000). En definitiva, se pone en evidencia una serie de «concesiones públicas» que revierten claramente en beneficio del interés privado, y que representó la entrada de conglomerados de empresas sin experiencia en este ámbito y de gran tamaño.

A continuación, se detalla los efectos sobre la responsabilidad pública que tienen estas modalidades de relación público-privadas.

\section{2. ¿Dónde reside la responsabilidad pú- blica?}

Admitiendo que la Administración establece relaciones con actores privados (con y sin ánimo de lucro) para la prestación directa o indirecta de servicios, no existe una lectura homogénea respecto al carácter de dicha relación, dándose dos grandes enfoques (neo-empresarial y neopúblico) sostenidos por ideologías contrapuestas que representan modos de relación públicoprivada diferenciados, tal como plantea Ramió (2000) y sintetizo en el Cuadro 1.

\begin{tabular}{|c|c|}
\hline Corriente neoempresarial & Corriente neopública \\
\hline $\begin{array}{l}\text { - Filosofía de «no remar» sino de hacer que los } \\
\text { otros «remen». Se apuesta por el Estado relacional } \\
\text { y la Sociedad del bienestar más que por el Estado } \\
\text { intervencionista y de bienestar } \\
\text { — Fomentar la mutación de las administraciones } \\
\text { públicas al pasar de proveedoras de servicios pú- } \\
\text { blicos a intermediarias que «venden» servicios. } \\
\text { — Reducción de la relación entre la Administra- } \\
\text { ción y la ciudadanía a la relación Administración- } \\
\text { clientes. } \\
\text { - Fragmentación de la Administración en unida- } \\
\text { des más pequeñas con una creciente autonomía } \\
\text { respecto a la gestión para que éstas se especialicen } \\
\text { en la producción de una gama determinada de ser- } \\
\text { vicios y se reajusten con más facilidad a las nece- } \\
\text { sidades de los clientes de los servicios públicos. } \\
\text { — Todo lo anterior se materializa en organismos } \\
\text { que tienen unas formas jurídicas alejadas en mayor } \\
\text { o menor grado del Derecho público. }\end{array}$ & $\begin{array}{l}\text { - Se refuerza el concepto de ciudadanía para que } \\
\text { permita la expresión activa de las opiniones. El } \\
\text { concepto de ciudadanía ha de servir para, median- } \\
\text { te un discurso abierto y pluralista, recrear la legiti- } \\
\text { midad política en la Administración Pública. } \\
\text { - Se deben reforzar los valores de la cosa públi- } \\
\text { ca y del empleo público, creando una cultura ad- } \\
\text { ministrativa asociada tanto a la eficacia y a la efi- } \\
\text { ciencia como a la ética en la gestión pública. } \\
\text { — Reconocer nuevos derechos con garantía a } \\
\text { los/as ciudadanos/as. } \\
\text { — Actuar en los servicios públicos con principios } \\
\text { y valores como la universalidad y la igualdad, con- } \\
\text { trapuestos a los de economicismo y gestión. } \\
\text { - Incrementar la calidad y el número de servi- } \\
\text { cios públicos. }\end{array}$ \\
\hline
\end{tabular}

Cuadro 1. Modos de relación público-privada.

Fuente: Elaboración propia a partir de Ramió (2000). 
La corriente neo-pública implica un modelo de relación en el que la Administración sigue manteniendo un papel garantista y responsable de la titularidad pública, desde el sentido del estado socialdemócrata keynesiano. La corriente neo-empresarial, por su parte, se ve ejemplarmente ilustrada en el estudio de caso realizado en la medida que el rol de la Administración pasa de ser el principal responsable y proveedor a convertirse en un intermediario más que vende servicios. Ambas corrientes admiten el modelo mixto de titularidad pública y gestión privada, con mayor o menor protagonismo de la administración.

Los mecanismos que se despliegan desde la corriente neoempresarial generan cierta atmósfera en la que resulta difícil la identificación de responsables, tener referentes claros en los procesos y, lógicamente, interfiere en el ejercicio y, sobre todo, en la defensa del derecho. Interesa valorar qué consecuencias plantea para el reconocimiento y ejercicio del derecho el estar sometido al citado modelo neo-empresarial. Esta cuestión aparece de manera reiterada en las entrevistas realizadas a juristas y profesionales implicados, pudiéndose resumir bajo la expresión: «no da lo mismo». En definitiva, no ofrece las mismas garantías a la ciudadanía, tal y como se expone a continuación con ejemplos y citas textuales de trabajadores sociales y juristas que asesoran en la defensa del derecho:

2.2.1. Indefensión de la ciudadanía frente a competencias que deben ser asumidas directamente por la Administración. Sobre la cuestión concreta de la valoración de las situaciones de dependencia realizada por una empresa pública, se expresaba uno de los juristas entrevistados:

Eso no debería permitirse, es decir la potestad administrativa no puedo delegarla. Me da lo mismo la vestidura que le ponga, es una infracción claramente de una norma general. Segundo, a eso yo creo que la añades mayor inseguridad para el ciudadano. Mayor inseguridad para el ciudadano porque se participa ante un ente privado, ajeno a la propia administración, la propia administración que es la que debe garantizar el procedimiento, pues obviamente no tiene toda la información (ET1, p. 4).

Yo detecto claramente que el ciudadano está en una situación de inseguridad (...). La rela- ción no es simétrica. Evidentemente la relación nunca puede llegar a ser simétrica, porque claro la administración está ejerciendo ahí una potestad pero al menos arbitrar un mecanismo que no genere indefensión o inseguridad. Yo creo que sistema en ese ámbito genera una claramente inseguridad e indefensión (ET1, p. 3).

No existe posibilidad de control parlamentario y ciudadano sobre la Agencia porque, tal y como fijan sus estatutos, está sometida únicamente al derecho mercantil.

2.2.2. Dificultad a la hora de identificar responsables. Esta estructura diluida o híbrida entre lo público y lo privado dificulta la identificación de responsables, de referentes en los procesos y, todo ello, como manifiestan los/as abogados/as entrevistados/as, interfiere en la defensa del derecho:

Hombre, yo el problema lo veo en que la responsabilidad puede quedar diluida cuantas más órganos o entidades intervienen en un proceso más posibilidades hay de que traten de escurrir el bulto imputando la responsabilidad a otro, $\mathrm{y}$ ese es lo más grave (EA1, p. 2).

2.2.3. Gestión ineficiente. Se produce la pérdida de documentación de expedientes, falta de conocimiento específico sobre el funcionamiento de la Administración y de los servicios sociales de algunos/as profesionales, requerimiento en múltiples ocasiones de los mismos documentos, paralización del procedimiento por falta de un protocolo o de una instrucción administrativa, falta de coordinación entre los diferentes agentes que intervienen en el procedimiento, desconcierto de los profesionales que trabajan en los servicios públicos respecto al papel de los/as profesionales que trabajan en la mercantil, etc. Respecto a algunos de estos obstáculos e irregularidades visibles en el propio procedimiento administrativo, los/as expertos/as juristas entrevistados/as inciden en las consecuencias más directas sobre el derecho, algunos ejemplos:

- Respecto a las dilaciones en resolver, el «procedimiento administrativo tiene sus dilaciones indebidas ya por naturaleza, no hay procedimiento que se cumpla en sus plazos. Un derecho tardío lo que genera es una injusticia. 
Un fallecimiento de una persona durante la tramitación (...)» (EAO1, p. 2).

- Respecto a la impresión de estar inmerso en un camino repleto de obstáculos:

Utilizan la técnica del cansancio. O sea, en las relaciones patrimoniales, fase administrativa, a todo: «no, no, no, no, si no existe nexo causal». ¿Cómo que no existe nexo causal? Si lo tienen bien premeditado. Siempre es un: «no, no, no, no». Si el particular se cansa entre reclamaciones para arriba reclamaciones para abajo, a ver si el particular se cansa, y ya no se mete en juzgados, que ya resulta más caro (EAS2, p. 12).

\section{— El silencio por respuesta:}

Un trato denigrante y a lo mejor me quedo hasta corto. Me parece lamentable que la Administración no conteste nunca. Si tú me preguntas y yo no contesto, tú ¿qué pensarías?, que soy un maleducado ¿verdad? Pues esto es lo mismo. Pues entonces, ¿cómo debemos considerar a la administración? Que el administrado que es quien sustenta esa administración hace una pregunta y no le contesta. Pues está mal hacerlo. La ley arbitra mecanismos para que la administración conteste y pese a eso no lo hace, no lo hace. Yo he llegado a conocer casos donde se escribe hasta la reina, para buscar alguna respuesta y se desconoce el procedimiento, y la gente está desesperada (EAS2, p. 6).

No, normalmente, en el $90 \%$ de los casos nunca se responde. En todo caso también, si te responden a una queja, lo que te pueden responder es: "ha tenido una esta administración la queja, te damos el número tal de queja, y ya está»». Y si te he visto no me acuerdo, nunca se supo más de esa reclamación, de esa queja en qué ha quedado (EAS3, p. 4).
- La opacidad en su funcionamiento: «cuando no se sabe cómo se ha determinado el personal que la integra, los valoradores, en fin... ha sido, nadie hemos entendido por qué se ha hecho eso» (EG1, p. 2).

- No se genera empleo público y, lo peor, no hay un control sobre los procesos de contratación para asegurar las condiciones básicas de «publicidad, mérito y capacidad» ${ }^{5}$. En este sentido, ante la petición de información de la Sindicatura de Greuges, resulta sorprendente la afirmación realizada por la Administración de que el proceso cumplió con los principios de «publicidad, mérito y capacidad», sin hacer constar por quién estaba conformado el tribunal de selección. El tiempo ha dado la razón a estas denuncias y presunciones, y la prensa se ha hecho eco de la sentencia judicial del Tribunal contencioso-administrativo al respecto ${ }^{6}$.

La suma de todos estos argumentos señala la ineficiencia con la que está operando este sistema híbrido. Para la garantizar un derecho social, bajo los preceptos de la cultura de la legalidad, no da lo mismo que el servicio sea público que privado. La racionalidad social se impone a la racionalidad mercantil cuando se trata de responder a derechos sociales, tal y como se pasa a concluir.

\section{No da lo mismo}

En definitiva, estos ejemplos dan muestras que el modelo neoempresarial que se impone tiene una clara repercusión en la relación entre Administración, ciudadanía y empresa, imponiéndose una cultura consumista que plantea claras consecuencias en el debilitamiento de la ciudadanía. Además, la cultura de la legalidad se encuentra

5 En este sentido, como consecuencia de una denuncia sindical al procedimiento de contratación de la Agencia Valenciana de Prestaciones Sociales S.A. en el mes de julio de 2012 se publicó la sentencia en la que según medios de comunicación (El País, 14/07/2012) «El juzgado número 7 de lo Contencioso Administrativo de Valencia considera nulos «los actos decisorios de las contrataciones laborales efectuadas para ocupar puestos técnicos, administrativos y operarios al servicio» de esta empresa pública. La juez censura que en las contrataciones, que se realizaron en los primeros meses de 2007, no existió la publicidad necesaria, «conllevando esta ausencia la quiebra del principio de igualdad, principios que rigen cualquier caso de contratación pública, aunque no se trate de funcionarios».

6 «Dos primas, una sobrina y una esposa colocadas a dedo y alrededor de 150 contratados más en estos años sin pasar por ninguna prueba ni bolsa de trabajo y de forma ilegal, según sentencia. Para rematar el cuadro, nada menos que 52 personas - en torno al $25 \%$ de la plantilla - cobrando sin ocupar ninguno de los puestos de trabajo de la empresa que paga, que los cede ilegalmente a la Conselleria de Justicia y Bienestar Social de la que depende» (Levante EMV, 20 de setiembre de 2012). 
gravemente herida, y con ella, las garantías en el ejercicio de los derechos. Las consecuencias más destacadas de este creciente debilitamiento de aquello que llamamos responsabilidad pública bajo fórmulas difícilmente asumibles como «servicios públicos», son entre otras las señaladas por Ramió (2000) como:

a) La activación o la multiplicación de la corrupción. Muy estudiado por la literatura anglosajona es la situación de «captura» del regulador por el regulado: el regulador acaba regulando para proteger los intereses del regulado. Este fenómeno, difícil de prevenir, no se puede considerar como corrupción pero puede estimular actividades ilícitas. Un alto empleado público que tiene como función controlar un sector empresarial muy potente sabe que su carrera profesional prosigue de forma natural en el sector privado trabajando en manos de las potencias económicas que suelen ser los agentes que antes ha regulado ${ }^{7}$.

Es muy importante que los/as empleados públicos encargados \}de controlar y evaluar los servicios públicos externalizados estén socializados en valores públicos. Pero si los/as empleados/as públicos/as están socializados/as en valores de carácter neoempresarial, esto significa que son mucho más permeables a la captura y a posibles actos de corrupción.

b) La cesión de la agenda pública a actores privados: se suele decir académicamente que estamos ante una Administración relacional (ordenadora y diseñadora pero que no gestiona) en el marco de un gobierno multinivel.

Pero esta tendencia a la fragmentación no la persiguen los agentes privados que prestan servicios públicos que tienden, de forma natural, a la concentración económica hasta llegar a situaciones de pseudomonopolio. Con el tiempo se generan grandes empresas especializadas en prestación de servicios públicos que están vin- culadas a la vez al gobierno local, a los mesogobiernos (Estados o regiones) y a la Administración central. Estas empresas tienen una visión transversal del sistema público, visión integrada de la que carecen los diferentes niveles públicos y llegar a tener tanto poder que la agenda pública de las diferentes administraciones esté en sus manos.

Y a esta lista de Ramió (2000) cabría añadir dos efectos más contrastados en la investigación realizada:

c) El incremento de la cultura consumista, entendida como aquella que se edifica sobre la lógica privada, concibiendo a la ciudadanía como clientes individuales y reduciendo su espacio a temas micro en la regulación del consumo. El mercado supondría en este caso, una sumatoria de intereses individuales. Un ejemplo lo ofrecen Brugué y Gomà (1994, p. 21) cuando reconocen que la relación de un enfermo con un servicio de urgencias incorpora un elemento de dependencia inexistente en un intercambio comercial o que el trato que debe ofrecerse a un prisionero no es el mismo que el que recibe un cliente de un hotel. La dimensión política implica también que el/la ciudadano/a active mecanismos de reivindicación y defensa de sus derechos por la vía política, alimentando a la vez a la denominada rendición de cuentas societal ${ }^{8} \mathrm{y}$, por tanto, la cultura democrática. Frente a ella, la cultura consumista promueve una defensa individualista en la que no toda la ciudadanía dispone de los mismos recursos para la defensa de su derecho, puesto que depende de su capital relacional, su capital informacional, o incluso económico, pagando los servicios de un buen jurista para poder ejercer la defensa de aquello que se considera «lo mío».

d) Debilitamiento de la cultura de la legali$d a d$, evidenciada en una débil rendición de cuentas administrativa y legal, puesto que se impone la racionalidad económica frente al ethos burocrático y a la racionalidad social y

\footnotetext{
7 Fenómeno popularmente conocido como la «puerta giratoria».

8 Para Villoria (2010) recurriendo a la definición original de Smulovitz y Peruzzotti puesto que la definen como mecanismo no electoral, pero vertical de control de las autoridades políticas, que descansa en las acciones de un múltiple conjunto de asociaciones de ciudadanos y movimientos, acción que tiene como objetivo exponer errores gubernamentales, traer nuevas cuestiones a la agenda pública o activar el funcionamiento de agencias horizontales de accountability» (p. 57).
} 
normativa. A su vez, también se evidencia a través de la falta de transparencia, alimentada por instancias que median en la relación administración-ciudadanía bajo los parámetros del mercado, sin la obligación de responder a la pregunta, a la queja o a la demanda de información. En concreto, la llamada cultura de la legalidad debe suponer que la formulación y aplicación de leyes o normas es pública, que dichas normas persiguen el bienestar y la justicia colectiva, que la población conoce sus derechos y sabe cómo exigirlos y que el gobierno es el principal agente sometido al escrutinio y control social en la aplicación de las mismas, lo que exige la transparencia en la aplicación del derecho. En definitiva, tal y como afirma Villoria (2010)

Las normas necesitan provenir de un ente que nos dé garantías de credibilidad y honestidad, las normas necesitan ser aplicadas por un ente que nos asegure imparcialidad, de ahí la importancia de la existencia y respeto de unos marcos de integridad en la actuación de los Gobiernos» (p. 63).

No se pueden obviar las implicaciones éticas de aquello que llamamos público y que está soportado por la burocracia. Como señala Fernández, en el estudio preliminar que se recoge en la edición castellana de la obra de Du Gay (2012), los logros que podemos considerar más estimables de la burocracia son: «la eliminación de favoritismos y la corrupción, la fiabilidad en el tratamiento de los diferentes casos y la equidad en las respuestas adminis- trativas» (p. 22). Y refiriéndose el autor a las estrategias de mercantilización de lo público, añade que suponen una ruptura de los principios políticos constitucionales (como, por ejemplo, la responsabilidad de los políticos ante el Parlamento) y desvirtúan las relaciones tradicionales entre la esfera política y la de la Administración, pretendiendo que criterios relacionados con el mundo de los negocios sustituyan el ethos propio de las instituciones organizadas en torno a la racionalidad y la legalidad.

La responsabilidad pública también es política, si la ciudadanía no dispone de mecanismos directos para exigirla sólo le queda exigir la responsabilidad jurídica, verificando así la débil y limitada posibilidad de control político previsto en este sistema democrático. La judicialización de la política entraña, plantea Maravall (2003) que: «si los gobernantes limitan su responsabilidad política al veredicto de las elecciones, y si entre una y otra elección sólo están dispuestos a aceptar responsabilidades legales por sus actos, entonces la confrontación política se trasladará del parlamento a los tribunales» (p. 202). Si el terreno de los tribunales es el único escenario que le queda a la ciudadanía para ser escuchada, como expresa Santos (2005), implica que el marco político de la contractualización social acaba cediendo su sitio al marco jurídico y judicial de la contractualización individual. En definitiva, implica una pérdida de calidad democrática e incrementa la deslegitimación política y de la acción de gobierno.

\section{Referencias bibliográficas}

Álvarez, O. (2010). Las claves del Buen Gobierno en la Administración Pública. Granada: Comares.

Álvarez-Uría, F. (2002). Estado Social vs Neoliberalismo. Revista Acciones e Investigaciones sociales, 16, 13-23.

Bautista, O. D. (2007). La ética en la gestión pública: fundamentos, estado de la cuestión y proceso para la implementación de un sistema integral en los gobiernos. Base de datos E-Prints Complutense, 7529 (Disertación Doctoral). Recuperado de: http://biblioteca.ucm.es/tesis/cps/ ucm-t29799.pdf

Confederació Sindical de Comissions Obreres del País Valencià. (2007). Escenarios del presente y futuro en la cobertura, provisión y gestión de la atención a situaciones de dependencia en el País Valenciano. Valencia: Germanía.

Du Gay, P. (2012). En elogio de la burocracia. Madrid: Siglo XXI.

Brugué, Q. y Gomà, R. (1994, julio). Nuevos modelos de gestión y organización pública. Autonomies, Revista catalana de dret públic, 18.

Etxezarreta, M. (2009, octubre). La privatización de los servicios sociales y la salud. Ponencia presentada en VIII Jornadas autonómicas de la Asociación española de neuropsiquiatría. Va- 
lencia, España. Recuperado de: http://www.anticapitalistes.net/IMG/pdf_Etxezarreta_Jornadas_psiquiatria-Privatizacion_copia.pdf. (Consultado el 22 de febrero de 2012).

Levante EMV. (20 de diciembre de 2000). El Consell justifica la incorporación de capital privado en los servicios sociales por el «importante» déficit de recursos.

Levante EMV. (23 de septiembre 2012). UGT detecta enchufados en la firma de la dependencia.

Maravall, J. M. (2003). El control de los políticos. Madrid: Taurus.

Moreno, M. (2002). Régimen jurídico de la asistencia social. Madrid: Ministerio de Trabajo y Asuntos Sociales. Colección Estudios.

Ramió, C. (2000, octubre). Externalización de servicios públicos y corrientes neoempresariales: los problemas de la administración relacional en el contexto de un gobierno multinivel. Ponencia presentada en el V Congreso Internacional del CLAD sobre la Reforma del Estado y de la Administración Pública, Santo Domingo, República Dominicana.

Sajardo, A (1996). Análisis económico del sector no lucrativo. Valencia: Tirant Lo Blanch.

Santos, B. de S. (2005). Reinventar la democracia. Reinventar el Estado. Argentina: CLACSO.

Tornos, J. y Galán, A. (2007). La configuración de los servicios sociales como servicio público. Derecho subjetivo de los ciudadanos a la prestación del servicio. Madrid: Ministerio de Trabajo y Seguridad Social.

Villoria, M. y Wences, M. I. (2010). Cultura de la legalidad. Madrid: Catarata. 